\title{
PRIMER
}

\section{Ecological niche models in phylogeographic studies: applications, advances and precautions}

\author{
DIEGO F. ALVARADO-SERRANO and L. LACEY KNOWLES \\ Department of Ecology and Evolutionary Biology, Museum of Zoology, University of Michigan, Ann Arbor MI 48109-1079, USA
}

\begin{abstract}
The increased availability of spatial data and methodological developments in species distribution modelling has lead to concurrent advances in phylogeography, broadening the scope of questions studied, as well as providing unprecedented insights. Given the species-specific nature of the information provided by ecological niche models (ENMs), whether it is on the environmental tolerances of species or their estimated distribution, today or in the past, it is perhaps not surprising that ENMs have rapidly become a common tool in phylogeographic analysis. Such information is essential to phylogeographic tests that provide important biological insights. Here, we provide an overview of the different applications of ENMs in phylogeographic studies, detailing specific studies and highlighting general limitations and challenges with each application. Given that the full potential of integrating ENMs into phylogeographic cannot be realized unless the ENMs themselves are carefully applied, we provide a summary of best practices with using ENMs. Lastly, we describe some recent advances in how quantitative information from ENMs can be integrated into genetic analyses, illustrating their potential use (and key concerns with such implementations), as well as promising areas for future development.
\end{abstract}

Keywords: coalescent modelling, ecological niche models, phylogeography

Received 14 August 2013; revision received 2 October 2013; accepted 4 October 2013

\section{Background}

Building upon a tradition of interdisciplinary approaches, recent integration of ecological niche models (ENMs) in phylogeographic studies is improving our understanding of the processes structuring genetic variation across landscapes (Knowles 2009; Chan et al. 2011). Because ENMs generate information about abiotic preferences and tolerances of species (i.e. the existing fundamental niche sensu Peterson et al. 2011), and hence, estimates of the current, past and possible future potential distribution of species, they are invaluable tools (Scoble \& Lowe 2010; Chan et al. 2011; Svenning et al. 2011). ENMs are an independent data source that can be used to evaluate or develop phylogeographic hypotheses about the processes generating patterns of genetic variation in disparate taxa from virtually anywhere across the globe (reviewed in Richards et al. 2007).

Given the broad applicability of ENMs and the increasing availability of environmental data in the form of GIS (Geographic Information Systems) layers and of species' distribution data (the main inputs for ENMs,

Correspondence: L. Lacey Knowles, Fax: (734) 763-4080;

E-mail: knowlesl@umich.edu
Box 1), it is perhaps not surprising that ENMs are becoming widely used in phylogeographic studies, although its use remains taxonomically and regionally biased (Fig. 1). Developments in the different uses of ENMs in phylogeography have also progressed quickly. This includes the use of ENMs to: identify the potential location of past populations (e.g. Swenson 2006; Knowles et al. 2007; Morgan et al. 2011), characterize species environmental preferences and tolerances (e.g. Stockman \& Bond 2007; Wooten et al. 2010), evaluate adaption to local environmental conditions across populations (Fournier-Level et al. 2011; Banta et al. 2012), test whether niche divergence accompanies species divergence (e.g. McCormack et al. 2010; Kalkvik et al. 2012), evaluate alternative biogeographic hypotheses about community responses to climate change (e.g. Galbreath et al. 2009; Edwards et al. 2012), and provide quantitative information for predicting how distributional shifts might leave species-specific signatures in patterns of genetic variation (e.g. Knowles \& Alvarado-Serrano 2010; He et al. 2013).

In the following section, we review the different uses of ENMs in phylogeographic studies, highlighting the advantages and limitations of ENMs in each of these applications. In particular, we focus on the integration of 
ENMs with coalescent-based approaches, some of the potentially most insightful, but also challenging, applications of ENMs in phylogeography. We provide some guidelines for the successful implementation of ENMs, including a brief discussion of the assumptions and limitations of ENMs (Warren 2012). However, we do not cover in detail the theory behind ENMs or specifics of individual modelling approaches, for which there is an extensive literature (Guisan \& Zimmermann 2000; Guisan \& Thuiller 2005; Peterson et al. 2007; Elith \& Leathwick 2009; Franklin \& Miller 2009; Elith et al. 2010; Pearson 2010; Sillero 2011).

\section{Box 1 ENMs: an overview}

ENMs can be divided into correlative and mechanistic approaches (Peterson et al. 2011; but see Sillero 2011). Mechanistic approaches use biophysical properties of organisms to directly link functional traits with environmental conditions to determine areas where species may exist (Kearney \& Porter 2009; Dormann et al. 2012). Correlative approaches, on the other hand, focus on identifying statistical associations between the distribution of a species (or set of species) and environmental conditions without the identification of causal links. Although both mechanistic and correlative approaches can be integrated into phylogeographic studies and can be used in combination (Elith et al. 2010; Dormann et al. 2012), mechanistic approaches have had limited use because of the detailed information, beyond the sampling coordinates, they require. In this box, we focus on correlative approaches (hereafter referred to generically as ENMs), which rely on two sources of information: (i) distribution data and (ii) environmental layers. Below, we present a brief description of the steps involved in generating ENMs with some general guidelines (see also Table 2).

\section{Distribution data}

Distribution data can be compiled from primary surveys, natural history collections, published species ranges (e.g. Barnes \& Wagner 2004), or public databases (e.g. Natureserve, Patterson et al. 2007; GBIF, Telenius 2011). Although different sources contain information relevant for ENMs, the accuracy and precision of distributional data is tightly linked to their origin and format, and hence, all distributional data should be vetted (e.g. confirm taxonomic identities and screen for possible errors in recording collection point information). Once distribution data have been compiled and vetted, all presence records (and sometimes absence records) should be mapped into a predefined map coordinate system that matches the one from the environmental data. If geographic coordinates are not available, georeferencing that ideally quantifies geographic uncertainty (e.g. Wieczorek et al. 2004) might be used. Tools for removing redundant data (i.e. points in the same locality or that fall within the same grid cell of environmental data), which can artificially bias ENM predictions, are available (e.g. Warren et al. 2010); more complex methods of filtering redundant data, such as those-based on spatial variograms (Goovaerts 1998), could also be used.

\section{Environmental data}

Environmental data in the form of digital grids can be derived from field data, interpolated surfaces (e.g. climatic data from WorldClim; Hijmans et al. 2005), or remote sensing (e.g. landcover from MODIS, Friedl et al. 2002; for additional examples of available data see Richards et al. 2007; Pearson 2010). Once compiled, all environmental data (i.e. both data used to train the model and for projecting the distribution) need to be processed. Most commonly this involved either transforming the environmental data into raster grids with a single predefined map coordinate system with GIS software (Bolstad 2008). Techniques to deal with correlated variables, such as orthogonal transformations (e.g. principal component analysis) are available and should be considered whenever the goal of the study does not include the identification of the relative contribution of different environmental variables to the model.

\section{Model generation and calibration}

The performance of different algorithms for determining the association between species distribution and environmental variables (Table 1) may vary. Likewise, data requirements (e.g. requirement of presence/absence or presence only data or ability to deal with categorical environmental variables) and output (e.g. continuous vs. discrete prediction) differ among algorithms. Thus, algorithm selection choice depends on the characteristics of the data and goal of the study. Although no simple basis for algorithm selection exists, general guidelines for deciding which approach to use are available (reviewed in Thuiller et al. 2003; Elith et al. 2006; Peterson et al. 2007; Elith \& Graham 2009). After deciding upon an approach or group of approaches, sensitivity analyses of parameter settings (Haegeman \& Etienne 2010; Anderson \& Gonzalez 2011; Royle et al. 2012), as well as sensitivity analyses for the inclusion/exclusion of 
variables in the model (especially when the variables are highly correlated with each other, as it is commonly the case), should be conducted in conjunction with model selection procedures (e.g. Warren \& Seifert 2011). Tools for identifying optimal ENM models are freely available (Warren et al. 2010); yet, uncertainty associated with model selection and parameterization should always be assessed.

\section{Model validation}

Assessing the accuracy of a model is essential and can be accomplished by different means (Liu et al. 2009; JimenezValverde 2012), depending upon the model and data type used (for review of validation procedures see Pearson 2010; Peterson et al. 2011). Model validation should be performed using multiple alternative accuracy measurements (Hernandez et al. 2006; Lobo et al. 2008; Liu et al. 2009) and on independent data (e.g. occurrence data from a new survey of the species), or if sample size is limited, on pseudo-replicated partitions of the data (e.g. bootstrapping or jackknifing the data). It is important to note that model utility depends on the application intended, and hence, that the accuracy required from a model should be considered on a case-by-case basis. If generating projections of species distributions in the past or future, it may be possible to validate these projections using historical data (e.g. palynological, or fossil records) or using biophysical models as reference (e.g. Kearney et al. 2009), respectively.

\section{Model projection}

Once the model has been validated, it can be projected across different regions and/or for different time periods (PMIP2, Braconnot et al. 2007; e.g. using climatic variables estimated for the past or future; CliMond, Kriticos et al. 2012). However, it is always important to consider all potential errors that might impact both the accuracy of the model and the projection (see Table 2), and ideally, this uncertainty should be considered in all downstream analyses. The robustness of the projections to different climatic estimates (e.g. MIROC, CCSM3; Braconnot et al. 2007) and model parameterizations should also be considered.

\section{Ecological niche models}

The approaches collectively referred to as ENMs (Warren 2012) include different methods that aim to identify the environmental niche and potential distribution of species and/or communities (Ferrier \& Guisan 2006; Peterson et al. 2011; Svenning et al. 2011) (Box 1). This is accomplished by statistically establishing an association between the locations where a species (or set of species) live and the environmental conditions of these locations, or, as in the case of mechanistic models, by directly calculating the physiological tolerances of a species based on biophysical principles (Kearney \& Porter 2009). Although the exact procedure followed varies among methods (Table 1), all of them first establish the environmental space the species under study inhabits (hereafter referred to as suitable, as is commonplace in the literature; however, note that in this context, suitable refers only to the set of inhabited environmental conditions; see Anderson 2013). This environmental space is then projected onto a geographic space, finding the geographic areas where the suitable environment is represented (for details see Box 1). Although in principle both correlative and mechanistic ENMs can be used in phylogeographic studies, mechanistic approaches have seldom been used in phylogeography. Hence, our review is focused on correlative approaches.

Despite the insights of an integrative perspective in phylogeography (Knowles 2009) that ENMs can bring to phylogeography, ENMs are not without their own set of challenges and potential pitfalls (Elith et al. 2010). The realized distribution of a species at any point in time is of course conditioned by a plethora of factors, including those that may not be accounted for in an ENM but play an important role in structuring distributions, such as biotic interactions (Davis et al. 1998; Meier et al. 2010; but see Anderson 2013). In addition, individual populations may differ in their responses to particular environmental conditions because of local adaptation (Fournier-Level et al. 2011). This raises the possibility of not only inaccurate inferences from ENMs based on the entire species range (see below), but also that phylogeographic analyses might be compromised (i.e. local adaptation may impact gene flow rates and evolutionary responses to climate change, but the impact of such fitness variation on population genetic structure is not directly accommodated by typical phylogeographic models). These and other caveats should be considered and best practices used to minimize errors with ENMs (see Table 2). Fortunately, there have been significant advances for the generation and refinement of ENMs (Peterson et al. 2011).

To guard against inaccurate inferences, it is also important to first clearly define the phylogeographic question that is being addressed with information from an ENM. Because the assumptions, performances and data requirements differ among potential methods for ENMs construction (Table 1) (Elith et al. 2006; Peterson et al. 2011), the choice of a particular modelling approach 

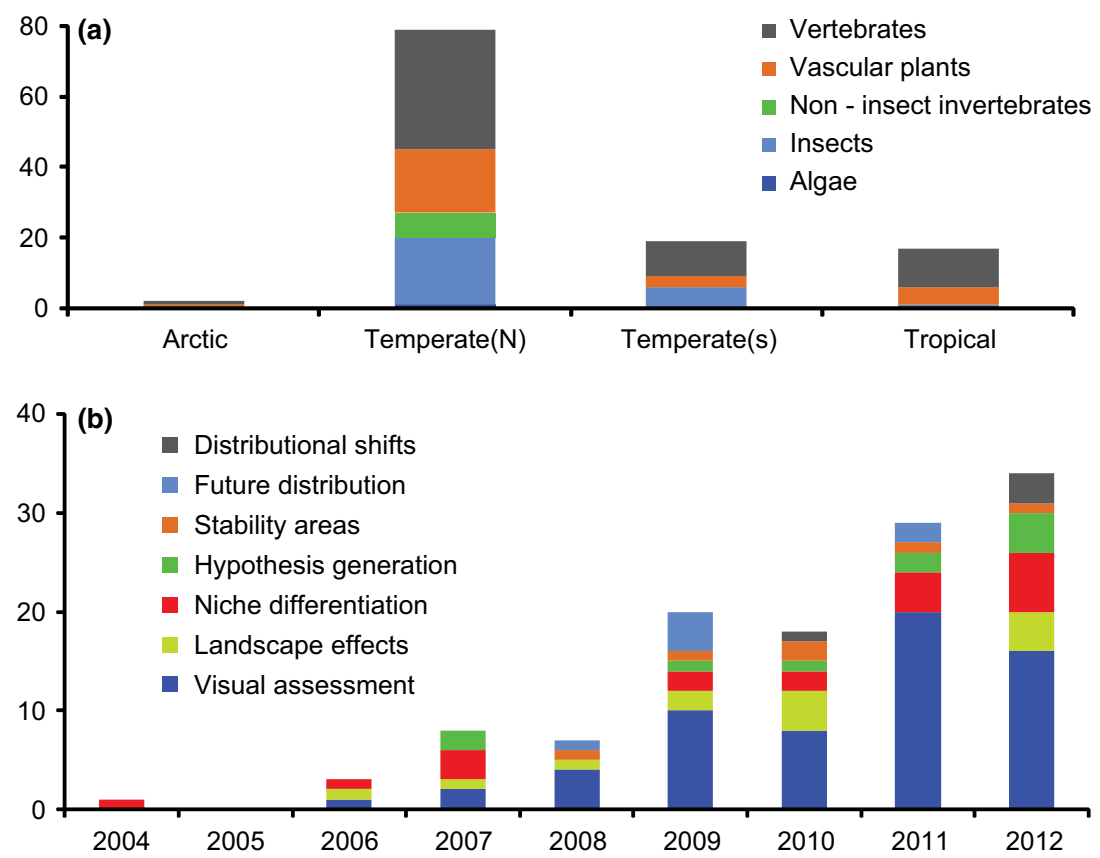

Fig. 1 Uses of ecological niche models (ENMs) in the phylogeographic literature. Number of articles recovered according to (a) the region and organism studied, and (b) how the ENM was applied given the year of publication; note that overall, $77.5 \%$ of studies to date used ENMs in a corroborative application (bottom three categories in legend), and only 22.5\% of studies used ENMs to generate phylogeographic hypotheses independent of genetic data. This summary is based on a search of articles containing the topic terms 'phylogeography' and 'niche model*' or 'distribution model*' on the Web of Science (the asterisk represents a wild card used to find words with alternative endings, for example, model ${ }^{*}=$ model, models, modelling). The results of this search were filtered to exclude all articles that did not include any of the following phrases in the abstract: 'niche model*', 'distribution model*', 'potential distribution*', 'ENM*', 'SDM*'. Although not exhaustive, this search procedure probably provides a fair representation of the available literature.

Table 1 Main distribution modelling methods available

\begin{tabular}{llll}
\hline Method & Procedure & Input & Reference \\
\hline BIOCLIM & Environmental envelope & Presence & Busby (1991) \\
HABITAT & Environmental envelope & Presence & Walker \& Cocks (1991) \\
DOMAIN & Gower distances & Presence & Carpenter et al. (1993) \\
GARP & Genetic algorithm & Presence/pseudoabsence & Stockwell \& Peters (1999) \\
Classification and Regression Trees & Regression & Presence/absence & De'ath \& Fabricius (2000) \\
Artificial Neural Networks (ANNs) & Machine learning & Presence/absence & Hilbert \& Ostendorf (2001) \\
Ecological Niche Factor Analysis (ENFA) & Eigensystem computation & Presence/background & Hirzel et al. (2002) \\
Generalized Linear Models (GLMs) & Regression & Presence/absence & Lehmann et al. (2002) \\
Generalized Additive Models (GAMs) & Regression & Presence/absence & Lehmann et al. (2002) \\
Support Vector Machines (SVMs) & Environmental envelope & Presence or presence/absence & Guo et al. (2005) \\
MAXENT & Maximum entropy & Presence/background & Phillips et al. (2006) \\
Multivariate Adaptive Regression & Regression & Presence/absence & Elith \& Leathwick (2007) \\
Splines (MARS) & & & Elith et al. (2008) \\
Boosted Regression Trees (BRTs) & Boosting & Presence/absence & Kitchener \& Rees (2009) \\
Deduced Distribution Model (DDM) & Expert knowledge & Presence/absence & Thuiller et al. (2009) \\
BIOMOD & Model combination ${ }^{1}$ & Presence/absence & \\
\hline
\end{tabular}

Depending upon the input, the specific procedures used in ecological niche models vary across methods. With presence only data, an environmental envelop approach is used in which environmental tolerances are determined from the environmental variables associated with specific occurrence records. In contrast, suitable areas are identified by contrasting the environmental conditions from known species occurrences against those (i) where the species is known to be absent (presence/absence models), (ii) is presumed to be absent (presence/pseudoabsence models), or (iii) against the environmental variation across the study region (presence/background algorithms).

${ }^{1}$ Combining models should be carefully considered as there is a risk of obtaining positively mislead answers (analogous to problems with concatenation in phylogenetics). 
Table 2 Summary of some basic considerations when generating ecological niche models (ENMs) (for a more extensive discussion and details see Barry \& Elith 2006; Soberón \& Nakamura 2009; Elith et al. 2010; Peterson et al. 2011)

Assumptions that may compromise ENM accuracy

Specific considerations

Relevant references

1. Data compilation

Are species presences (and absence) records representative of the actual distribution?

Do environmental variables accurately capture the association between species subsistence and the environment at the relevant scale?

2. Model generation and calibration Is the modelling algorithm appropriate given the data available and research question?

Is the model appropriately calibrated for the data available and research question?

3. Model validation Is validation performed on truly independent data and under appropriate settings?

\section{Model projection}

Is the species-environment relationship likely to be maintained in space and/or time?
- effects of species' natural history

- geographic/environmental bias

- intraspecific variability

- positional uncertainty

- sample size

- sampling bias (e.g. towards

more accessible areas)

- taxonomic accuracy

(e.g. subspecies or races)

- temporal coverage

in relation to environmental data

- data quality and biases

- effect on species distribution

(direct vs. indirect)

- resolution in space and time

- spatial autocorrelation

- spatial extent

- temporal coverage and stability

- type (categorical vs. continuous)

- algorithm assumptions

- algorithm performance

under different scenarios

- input data type (e.g. presences only

vs. presence/absences)

- output generated (e.g. presence/absence

vs. continuous prediction)

- sensitivity to model parameters

- model complexity

- model selection procedure

- setting of model parameters

- variable selection strategy

- assumptions/limitations of accuracy measurement

- importance of use of multiple metrics

- sensitivity to model parameters

- threshold transformation of

continuous predictions

- availability of validation

data in projected regions

- likelihood of niche shifts

- model uncertainty

- model transferability

- risks of interpolation

and extrapolation
Stockwell \& Peterson (2002), Hernandez et al. (2006), Pearson et al. (2007), Hortal et al. (2008), Jackson et al. (2009), Lozier et al. (2009), Phillips et al. (2009), Barve

et al. (2011) and Gonzalez et al. (2011)

Van Niel et al. (2004), Barry \& Elith (2006), Anderson \& Raza (2010), Kriticos \& Leriche (2010), Pearson (2010), Barve et al. (2011), Peterson et al. (2011) and Synes \& Osborne (2011)

Austin (2002), Segurado \& Araujo (2004), Pearson et al. (2006), Guisan et al. (2007), Elith \& Graham (2009) and

Barbet-Massin et al. (2012)

Maggini et al. (2006), Anderson \& Gonzalez (2011), Austin \& Van Niel (2011) and Warren \& Seifert (2011)

Fielding \& Bell (1997), Liu et al. (2005), Hirzel et al. (2006), Peterson et al. (2008) and Elith \& Graham (2009)

Thuiller et al. (2004), Randin et al. (2006), Peterson et al. (2007), Elith et al. (2010),

Peterson (2011) and

Wenger \& Olden (2012) 
will vary depending upon the application. For example, if the goal is to estimate the similarity of niches between phylogeographic lineages, a regression-based model, which is not particularly robust to spatial autocorrelation, should be avoided (Sokal \& Rohlf 1981). Likewise, if the goal is to generate projections of past distributions, ENM approaches, such as environmental envelope models, should be avoided as they are not ideal for such applications because of sensitivities with extrapolating to conditions that are beyond those used in the training set (i.e. when current environmental conditions are a small subset of those present at different time periods) (Fielding \& Bell 1997; Roberts \& Hamann 2012a). The spatial structure of the taxon of interest is another important consideration when selecting a modelling approach. For example, broadly distributed species are often composed of locally adapted populations with distinct environmental tolerances and potential ranges (Fournier-Level et al. 2011; Banta et al. 2012). Under this scenario, communitybased approaches that allow for the modelling of each population independently may be a well-suited alternative to species-based models that assume a common response of populations across the entire species range (Crego et al. 2013; Gray \& Hamann 2013; for a comparison of these approaches see Chapman \& Purse 2011).

\section{Applications of ENMs in phylogeographic studies}

Here, we review some of the common uses of ENMs in phylogeographic studies. The application of ENMs vary, with ENMs most commonly used in a correlative (or corroborative) manner vs. as tools for generating hypotheses (or predictions) that can be tested with genetic data (Fig. 1). This reflects in part the differences in the type and availability of required data for specific applications (i.e. whether physiological data or genomic data might be needed), as well as differing levels of analytical development across applications (i.e. some new applications discussed below show promise but require further development for their full potential to be realized).

\section{Visual assessments of concordance with genetic variation}

One of the most common applications of ENMs in phylogeography (Fig. 1b) is to interpret patterns of genetic variation based on the post hoc concordance between patterns of genetic divergence and projections of the species distribution. For example, a deep phylogenetic split between geographically proximate populations may be suggestive of long-term isolation. Support for this hypothesis might be obtained by visual inspection of projections of past species distributions (i.e. from ENMs based on paleoclimatic variables), where the distributional disjunctions correspond to the genetic differentiation observed between regions (e.g. Moussalli et al. 2009).

These analyses are typically qualitative, seeking corroborative evidence visually from the ENMs, and are often implemented in one of two ways. An ENM may be generated for the entire species of interest and compared visually to the pattern of genetic variation, for example, to identify plausible isolating barriers (e.g. areas of low suitability) or past distributions during glaciations that may explain observed genetic breaks (e.g. Beatty \& Provan 2010; Lawson 2010). Buckley et al. (2009), for example, compared the spatial arrangement of genetic diversity of a New Zealand stick insect (Argosarchus horri$d u s)$, to past distribution models created from all reliable records of the species. With geographic regions of high and low genetic diversity coinciding with suitable and unsuitable regions identified by the ENMs, respectively, these authors conclude that it is probably that differences in genetic diversity across the species range reflects differences in population persistence during glacial periods.

Alternatively, ENMs can be generated separately for each group of individuals (or populations) identified from genetic analyses and the geographic overlap of the projected distributions of the different genetic groups assessed (Jezkova et al. 2009; Banta et al. 2012; Hornsby \& Matocq 2012). For example, to evaluate the role of environment differentiation in the divergence of three distinct genetic lineages of the Spanish lizard (Psammodromus hispanicus), Fitze et al. (2011) modelled the current distribution of these three distinct genetic lineages. With marginal overlap in their predicted distributions, the authors conclude that the ENMs support a hypothesized role of environmentally driven isolation as a driver of divergence in this lizard.

Because these applications are correlative, ad hoc interpretations might be misleading given that other processes might have generated the observed genetic patterns (Box 2; Wagner \& Fortin 2013). This is especially a concern when the landscape has been dramatically altered (such that genetic variation may be associated with past, rather than current, landscape configurations; see Zellmer \& Knowles 2009), the species distribution has been historically dynamic (as with climate induced distributional shifts; see Hewitt 2000; Greenstein \& Pandolfi 2008), or the distribution of a species is structured by biotic interactions not captured by the ENM model (Wisz et al. 2013).

\section{Identification of landscape effects}

This application is focused on correlative tests between landscape features and patterns of genetic variation and/or gene flow (inferred from genetic data). Using 
habitat suitability scores from ENMs, the impact of the landscape on population connectivity can be predicted. For example, habitat suitability information can be translated into probable migration paths between populations using either least-cost path analysis or isolation by resistance calculations (McRae 2006). The resulting matrix of pairwise connectivity values among populations is then statistically compared with a corresponding matrix of pairwise genetic distances or genetic diversity using regression or ordination methods (e.g. canonical correspondence analysis; ter Braak 1986) or correlation methods (e.g. Mantel tests; Mantel 1967). For example, using a series of Mantel tests, Ortego et al. (2012) examined the explanatory power of current vs. the past distribution (during the last glacial maximum) from ENMs with respect to patterns of genetic relatedness of an endemic oak from southern California (Quercus engelmannii). Their analyses showed that both current and past distributions, in addition to elevation, were significant predictors of pairwise genetic distance, even after accounting for the geographic distance between populations, indicating the joint influence of current and historical landscape configurations on genetic structure of the species.

Alternatively, spatial association methods (e.g. boundary overlap statistics, Jacquez 1995) can be used to statistically determine whether spatial breaks in the ENM-based suitability of habitats (as identified from boundary delineation methods; Fortin et al. 1996) overlap with genetic boundaries (such as those estimated using Monmonier's or Womble's bilinear algorithm; Monmonier 1973; Barbujani et al. 1989) (reviewed in Legendre \& Fortin 2010; Wagner \& Fortin 2013). Such analyses, for example, were used to assess whether the dispersal of foxsnakes in Canada and northern US was limited by habitat degradation (Row et al. 2010). Using assignment tests that explicitly incorporate spatial information of the samples (e.g. Corander \& Marttinen 2006; Chen et al. 2007) coupled with spatial interpolation to identify the location of genetic breaks, Row et al. (2010) were able to show that patterns of genetic differentiation were spatially coincident with areas of low habitat suitability, as determined by the ENMs, supporting the impact of habitat suitability on population connectivity in these snakes.

As with applications that seek concordance (discussed in the previous section), the correlation between the landscape, or habitat suitability and genetic data may not be causal. For example, genetic patterns may not be exclusively linked to the present landscape configuration, but instead reflect the past configuration of habitats or the effects of range shifts themselves (Knowles \& Alvarado-Serrano 2010; He et al. 2013). Tests of the role of past population connectivity in shaping current patterns of genetic diversity (e.g. when past and present landscape configurations differ; Zellmer \& Knowles 2009) are also for populations in mutation-drift equilibrium (i.e. they assume that the rate of input of new mutations is equal to the rate of loss of mutations by genetic drift). Furthermore, they generally view current genetic diversity as a simple product of environmental isolation (i.e. they do not consider how species-specific characteristics that might affect local population demography would impact the relationship between genetic divergence and landscape configurations; Chan \& Hadly 2011).

\section{Niche differentiation}

There are several different ways ENMs can be used to examine whether different phylogeographic lineages may have diverged in their respective niches (Peterson et al. 2011). Niche similarity can be assessed by evaluating whether an ENM generated for one phylogeographic lineage recovers the distribution of another (Peterson et al. 1999; Warren et al. 2008). Alternatively, the spatial or environmental overlap of ENMs generated for different phylogeographic lineages can be assessed (e.g. Warren et al. 2008; McCormack et al. 2010). For example, niche divergence across many different environmental factors might be assessed by ordination, in which the distribution of phylogeographic lineages across environmental space, or differentiation along environmental axes, is characterized (e.g. Graham et al. 2004). Regardless of the chosen method, a diversity of questions related to niche differentiation can be addressed with the coupling of genetic data and ENMs in this context. These include the importance of local adaptation among populations (Fournier-Level et al. 2011; Banta et al. 2012) and species diversification (e.g. Beukema et al. 2010; Kozak \& Wiens 2010), tests of the likelihood of niche conservatism (e.g. Cordellier \& Pfenninger 2008), delimitation of species (e.g. Rissler \& Apodaca 2007), or even cryptic speciation (e.g. Florio et al. 2012).

When ENMs are applied to study niche differentiation, some interpretations need to be made cautiously. As a sole measure of niche differentiation, ENMs obviously may not capture all dimensions relevant to defining a species niche (for discussion see Guisan \& Thuiller 2005; Soberón \& Peterson 2005; Kearney 2006; Soberón 2007; Sillero 2011; Warren 2012). Tests of niche divergence, including those that test for divergence relative to a particular background level (e.g. McCormack et al. 2010; Warren et al. 2010) can be sensitive to the environmental variables included in the analyses (see McCormack et al. 2010; Rodder \& Lotters 2010). Likewise, when species distributions don't overlap spatially, differences in the niches characterized from the ENMs may not have an adaptive explanation (Ree \& Sanmartin 2009). It may, for example, reflect that the taxa simply occupy different geographic regions, which could reflect the mode of 
speciation (e.g. isolation by a geomorphic feature that acts as a barrier to dispersal). Nevertheless, to the extent that ENMs capture relevant aspects of the niche (e.g. environmental tolerances), ENMs can provide valuable insights about niche similarity or divergence (as highlighted by the studies referenced above), not withstanding certain limitations.

\section{Generation of hypotheses}

Rather than seeking visual corroboration or correlations between information from ENMs and patterns of genetic variation, ENMs can instead be used to generate hypotheses that are subsequently tested with genetic data (Richards et al. 2007). This approach generally consists of using ENMs to identify population distributions for the present and/or past that can inform the choice of particular phylogeographic models to test (e.g. Lehrian et al. 2010; Ralston \& Kirchman 2012). With the identification of discrete populations, demarcated by regions of low predicted occurrence from an ENM (and perhaps different ancestral source populations in the past), expected patterns of genetic variation can be generated for these ENM-informed scenarios using coalescent simulations (Carstens \& Richards 2007). This general framework can also be used to test hypotheses (Knowles 2009). For example, genetic simulations were used to test whether contemporary populations were founded from one common glacial refugial population, as opposed to different ancestral source populations in montane grasshoppers (Melanoplus marshalli) from the Rocky Mountain sky islands (Knowles et al. 2007). The hypotheses were in this case inspired by an ENM based on paleoclimatic data that identified more than one possible refugial population. The estimated habitat suitability differed between refugial areas, which raised the question of whether the montane populations were actually colonized from only one of the two putative glacial refugia - a hypothesis that was rejected based on coalescent simulations tested under the models (Knowles et al. 2007).

A primary challenge with this application of ENMs revolves around the translation of information from the ENMs into models (i.e. hypotheses about the processes generating patterns of genetic variation). There may be many different configurations of possible current populations and/or routes of colonization from past populations. For example, differing habitat suitability levels may not clearly delimit geographic regions that have been more or less isolated. The models generated from the visual inspection of projected distributions from ENMs also may not capture the primary demographic events experienced by a species. Co-distributed species may not exhibit similar patterns of genetic variation for a particular landscape configuration, for example, because of differing dispersal capabilities, ecologies and/or natural histories that leave different genetic signatures as taxa experience species-specific bottlenecks and/or rates of population expansion as they move across a landscape (Knowles \& Alvarado-Serrano 2010; Marske et al. 2012).

Although it is important to remain cognizant of these caveats, these challenges represent a more general constraint of model-based inference in phylogeography. In fact, the independent information ENMs provide are an important source for generating hypotheses about the processes impacting patterns of genetic variation. As such they can be key in developing models that can then be tested using a variety of statistical phylogeographic approaches (reviewed in Knowles 2009; Beaumont et al. 2010; Hickerson et al. 2010).

\section{Areas of stability}

Predictions for species distributions at different time periods from ENMs can be used to identify regions of environmental stability where a species may (in principle) have persisted overtime, in contrast to unstable areas (i.e. areas where climatic changes would have made the region uninhabitable during particular periods). For example, Carnaval et al. (2009) assessed the geographic overlap between projected distributions of tropical forests along the Brazilian coast to identify areas of stability over the last 21000 years (i.e. since the last glacial maximum) that might have served as refugia. Such areas represent areas of critical conservation concern given the extent of deforestation of the Brazilian coastal forest and as species survival under climate change scenarios become increasingly more pressing. By collecting genetic data on three frog species, they were able to show that, as predicted, populations from stable areas identified from the ENMs not only exhibited a genetic signature that differed from those in unstable areas, but that the genetic patterns were also consistent with long-term population persistence in all three species (based on a hierarchical approximate Bayesian computation analysis).

Of course the environmental (or climatic) stability of an area may not correspond to the ecological stability of an area. Nonanalogue communities can be common, indicating that even for co-distributed species, areas of stability may differ among taxa (Williams \& Jackson 2007; Polly \& Eronen 2011). There can also be potential problems with identifying areas of stability associated with the statistical procedure of projecting the ENM beyond the data used to train it (i.e. projecting the distributions for combinations of environments not present today). Different ENM algorithms deal with this problem in different ways, but the majority of methods constrain the suitability of novel environments to remain within that of the training environment (a procedure referred to as 
'clampling'; Elith et al. 2011). To deal with this issue, for example, recent implementations of Maxent generate lower suitability scores in areas with environmental conditions not represented in the training data, effectively extending the suitability values of the maximum (or minimum) environment conditions to all environments outside the range of the data used in the training set (cf. Maxent help file; Phillips et al. 2006). This introduces a risk of identifying areas of stability from the models simply because of the increased uncertainty of the projected distributions across different time periods (e.g. larger areas of suitability will be represented in ENMs across time periods characterized by conditions not present in today's climate, which may fall outside the physiological tolerances of the species; Soberón \& Nakamura 2009). Inflation of the geographic scope of suitable habitats that leads to the false characterization of stable areas overtime will create downstream problems when interpreting the results from phylogeographic analyses. For example, the importance of stable areas as a key determinant of population genetic structure might be rejected because of misspecification of what were stable and unstable areas. Unfortunately, accounting for uncertainty in ENMs is area in need of further development (see discussion below), but approaches for identifying areas with nonanalogue conditions (see Roberts \& Hamann 2012b) could be used to guard against misleading conclusions in phylogeographic tests of the importance of climatic stability.

An additional concern with identifying regions of stability reflects the inherent limited temporal resolution of climatic data for generating ENMs. Specifically, ENMs are typically generated for fixed temporal snapshots (but see Brown \& Knowles 2012), leaving open the possibility that suitable habitats (and populations) could have shifted repeatedly in a manner that was not always spatially concordant overtime, and/or with a frequency that is beyond the temporal resolution of the climatic data used for generating ENMs for different time periods (Graham et al. 2010). Despite these potential limitations, when coupled with tests of expected genetic signatures for areas of stability (e.g. higher genetic diversity, no evidence of bottlenecks) and/or a statistical hypothesistesting framework (e.g. likelihood or Bayesian methods; for review see Nielsen \& Beaumont 2009), using ENMs to identify areas of stability for phylogeographic studies can be particularly revealing (e.g. Werneck et al. 2012; Fuchs et al. 2013).

\section{Future distributions}

With rising concerns about the impact of current climate change on species, ENMs offer a potential tool for assessing potential future consequences. However, because of a number of challenges, such applications have been limited (Fig. 1b). Not only could there be errors in accurately predicting the configuration of climatic variables in the future, the factors that limit species distributions today may not be the same in the future. This may be especially true if climate change produces unique combinations of environmental conditions that a taxon has not experienced in the past (Williams \& Jackson 2007) or if the response of a species to climate change is compromised by mismatches between the distribution of adaptive alleles and local environmental conditions (Banta et al. 2012; Gray \& Hamann 2013), making predictions about the genetic consequences of future climate change challenging.

Nevertheless, by creating ENMs for independent phylogeographic lineages under different climate change scenarios, a suite of possible effects on the genetic diversity of species can be considered. For example, by assessing the overlap between protected areas and future ENM-predicted distributions of distinct lineages of nine species of African large mammals, D'Amen et al. (2013) were able to forecast the likelihood of lineage persistence, and hence, the expected impact of global warming on genetic diversity in these mammals. Examination of the ENMs for similar distributional effects between the future and past (e.g. similar range reductions or levels of fragmentation) may also provide a window into how future climate change will impact species by drawing analogies from genetic signatures of past distributional shifts (e.g. Taubmann et al. 2011). Such inferences may be improved upon further by incorporating physiological data that identifies what environmental factors are key to predicting the response of species to environmental change. For example, using physiological data on larval mosquitoes (Aedes aegypti), Kearney et al. (2009) were able to not only predict, but also to show that expected distributional shifts from ENMs were realized in Australia under recent historical changes in human water-storage practices. Their results demonstrate how human practices mediate the impact of global climate change on species, assessing the expected effects of physiological evolution in these mosquitoes in response to climate change. Yet, translating the genetic consequences of expected distributional shifts can be difficult because of the varying demographic effects that can accompany these shifts (Excoffier et al. 2009; Arenas et al. 2012).

\section{Expanding the content from ENMs used in phylogeographic studies}

Although ENMs provide quantitative spatial information that is commonly used in phylogeographic studies (i.e. the suitability of an area, and hence, how the predicted occurrence of a species varies across the landscape), ENMs contain additional information, and in particular 
quantitative information, that is seldom incorporated into phylogeographic studies. In this section, we overview some promising areas of development related to developing suites of phylogeographic hypotheses/models and generating species-specific genetic expectations. Like the applications discussed above, these too share some of the common challenges (see Table 2), and they are not repeated here. Moreover, such applications have not been explored thoroughly, and therefore, should be used cautiously. We include them here primarily to highlight directions for future development and to suggest new ways in which ENMs might be integrated with genetic analyses to broaden the scope of phylogeographic hypotheses that might be tested.

\section{Accounting for uncertainty in an ENM}

The process of translating information from an ENM into a hypothesis and/or model has the potential to incorporate uncertainty of the ENM into phylogeographic tests with genetic data. The goal here is to avoid treating the information contained in an ENM as fixed and without potential biases or errors. For example, a suite of different biogeographic histories might be translated from an ENM if we consider how the number and/or levels of connectivity among populations may vary depending on the threshold used to infer occurrence across the landscape, (e.g. 4 isolated populations might be apparent for habitat suitabilities above $85 \%$, but only 2 regions with a narrow connecting corridor might be inferred for habitat suitabilities above $40 \%$ ). In other words, different interpretations of the ENM can alter the spatial configuration of potential populations and consequently have important ramifications for intuiting phylogeographic hypotheses from ENMs. Likewise, uncertainty associated with the quality of the available data could be quantified (e.g. issues with irregular sampling or spatial dependency; Latimer 2007) and ideally incorporated into downstream analyses. However, this area remains undeveloped.

\section{Incorporating information about distributional shifts}

Environments are not constant and populations are not static (in location or size), as evidenced by the vast literature on climate-induced distributional shifts (e.g. Stewart 2009; Shafer et al. 2010; Allal et al. 2011). Although paleoclimatic data provide an opportunity to estimate past distributions (e.g. Knowles et al. 2007; Buckley et al. 2009; Smith et al. 2011; Marske et al. 2012) and there have been advances on studying movement patterns across spatially or temporally variable landscapes in other fields, such as conservation planning (e.g. Iverson et al. 2004; Lawler et al. 2013), little phylogeographic research has explored the issue of how to represent the movement of species from one point to another on the landscape across different time periods (but see Graham et al. 2010; Brown \& Knowles 2012). Theoretical work suggests disentangling the effects of spatial vs. spatio-temporal processes may be difficult (Wegmann et al. 2006). Considering both the spatial and spatiotemporal components of distributional shifts may nonetheless be important from a biological perspective. For example, it may be the rate of change in available habitats, not the spatial configuration itself, that is key to understanding why some species diversify during dynamic geologic periods and others do not (Knowles 2000). Nevertheless, the predominant approach of incorporating information from ENMs for different time periods focuses on the spatial component of distributional shifts, and they do not consider associated demographic changes in populations' size accompanying shifts in the distribution predicted by ENMs at different time points (Richards et al. 2007).

A couple of different recent approaches have taken advantage of the quantitative information contained in ENMs (i.e. differences in the habitat suitability scores across the landscape) to extract more detailed information about the spatiotemporal component of distributional shifts by coupling ENMs projected for different time periods. For example, an amalgam of the ENMs from different periods might be generated (e.g. an average habitat suitability surface; Knowles \& Alvarado-Serrano 2010). Alternatively, local suitability scores might be defined by a weighted average that varies for each time period according to the amount of time that separates these periods from the projected ENMs (see Brown \& Knowles 2012; He et al. 2013), to account for gradual shifts in habitability of geographic regions over time. When coupled with independent information about the rate of climate change, such as information from oxygen isotope ratios, different rates of climatic change, and accompanying shifts in the distributions, might also be calculated for the intervening periods for which paleoclimatic data is available (see Brown \& Knowles 2012).

These promising (albeit underdeveloped) approaches all address the spatiotemporal component of distributional shifts, but do not consider how species are moving across the landscape. Such a static view of what is a complex dynamic process could potentially be misleading (Dyer et al. 2010; Wagner \& Fortin 2013). For example, high levels of genetic differentiation among populations might reflect long-term isolation of the current populations, founding of the populations from separate refugial populations, or, as recently shown by simulations, result from the demographic process of colonizing contemporary populations from a single shared ancestral population (Knowles \& Alvarado-Serrano 2010). In the following section, we highlight two approaches that utilize the quantitative information contained in ENMs to 
inform the demographic component of distributional shifts, as well as other phylogeographic models more generally.

\section{Generating species-specific predictions for patterns of genetic variation}

With quantitative information on differences in habitat suitability across a landscape at different time periods, there is the potential to use this information on predicted distributions to infer how individuals have possibly dispersed (Crandall et al. 2012). For example, an estimate of the history of population connectivity over time might be generated using an optimization algorithm to identify a probably migration path (Graham et al. 2010). Specifically, with suitable areas identified at different time points from ENMs (i.e. those generated from contemporary climatic data and paleoclimatic data, respectively), the most likely spatiotemporal path can be selected using a pre-defined criterion, such as minimum cost path. As with landscape genetic approaches, there are still potential problems with selecting a single path given that multiple, complex migration paths may be involved (see McRae 2006). Yet, with such a species-specific estimated history of population connectivity over time, the resulting information can be used for testing models of isolation by distance that account for how genetic differentiation may have been impacted by population connectivity patterns that change over time.

Alternatively, expected patterns of genetic variation can be generated for a diversity of different models for testing phylogeographic hypotheses using iDDC modelling (integrative distributional, demographic and coalescent modelling; He et al. 2013) (see also the approaches described in Ray et al. 2005; Neuenschwander et al. 2008). Briefly, with the iDDC approach (Fig. S1) habitat suitability scores are extracted from an ENM across a landscape to inform a spatially explicit demographic model, in which population sizes and migration rates track local habitat suitabilities, and the parameters from the demographic model are used to inform a spatially explicit coalescent model. DNA sequences are simulated upon these coalescent genealogies to generate expected patterns of genetic variation across the landscape (see Knowles \& Alvarado-Serrano 2010 for details). As local population sizes and migration probabilities are informed from the local habitat suitabilities estimated from the ENM, the iDDC modelling approach generates patterns of genetic variation that reflect the interaction of the biological and physical factors that determine population connectivity, not just landscape features alone. Moreover, the likelihood of different models can be assessed, along with the estimation of demographic parameters, with the iDDC approach using flexible statistical tests, like Approximate Bayesian Computation, ABC (Beaumont 2002), which can accommodate complex, biologically informed models. For example, He et al. (2013) used iDDC modelling to test hypotheses about the factors structuring patterns of genetic variation in a southwestern Australian lizard, Lerista lineopunctula$t a$. As a sand dune specialist, it was conceivable that population divergence could reflect the contemporary habitat configuration, which limits migration among the small geographically isolated populations (Excoffier et al. 2009). Alternatively, genetic variation might reflect the colonization patterns associated with historical shifts in suitable coastal sand habitats, which expanded and contracted during glacial and interglacial periods, respectively. Tests based on multilocus sequence data showed that a dynamic model that takes into account the demographic consequences of the species tracking it habitat under shifting climatic conditions was a more probable model than either a static model of isolated populations or one based on contemporary landscape features alone.

With the complex models accommodated by iDDC modelling, tests with $\mathrm{ABC}$ will not only require multilocus data, but also careful evaluation of the $A B C$ tests (Bertorelle et al. 2010; He et al. 2013). This includes meaningful selection of model priors in the light of empirical data (Lombaert et al. 2011; Hickerson et al. 2013), an appropriate number of simulations run for each model being tested (Beaumont 2002; Wegmann et al. 2010), the selection of informative statistics to summarize genetic variation under each model and the assessment of their interaction (Wegmann \& Excoffier 2010; Robert et al. 2011), and appropriate model selection and parameter estimation procedures (Neuenschwander et al. 2008; Leuenberger \& Wegmann 2010; Wegmann et al. 2010). Such quality control measures involve the use of pseudoobserved data (pods), which are simulations generated under a known scenario or set of scenarios and compared against a fixed set of parameter values, providing an assessment of whether the data (and summary statistics used) are sufficient for accurate estimation (Neuenschwander et al. 2008; Estoup et al. 2012) (for further details on model robustness and accuracy assessment see Thornton \& Andolfatto 2006; Guillemaud et al. 2010). If these precautions are followed, the $\mathrm{ABC}$ approach allows not only for the identification of the most likely scenario that may have generated observed patterns of genetic variation but also estimation of the parameters in the models (e.g. migration rates, times of divergence and population sizes).

\section{Conclusions}

The incorporation of ENMs into phylogeographic studies has made a significant contribution to the field of 
phylogeography, broadening the suite of hypotheses that can be tested, as well as advancing integrative methodological approaches. These contributions, in large part, reflect the utility of species-specific information obtained from ENMs, whether ENMs are applied in a corroborative manner, as most commonly done, or a formal hypothesis testing framework (reviewed here through illustrative examples, as well as a discussion of the caveats with specific applications). As such, the use of ENMs in phylogeography is instrumental for identifying the processes structuring genetic variation and revealing previously unrecognized mechanisms shaping the evolutionary trajectories of species and populations. In this regard, ENMs have also been key to moving the field of phylogeography towards the development of biologically informed hypotheses and away from generic statistical tests that provide little biological insight. The rapid methodological advances in the construction of ENMs, together with the increasing availability of geospatial environmental and species distribution data, will no doubt expand the ways in which ENMs might be used to address phylogeographic questions, continuing the impressive trajectory of their applications in phylogeography to date. While we highlight some of these new promising developments, more research is clearly needed, especially with regards to translating not just the qualitative information, but also the quantitative information contained in ENMs, into testable phylogeographic hypotheses.

\section{Acknowledgements}

We would like to thank and acknowledge the invaluable input of Qixin He, especially with regards to her insight and contributions to discussion and implementation of new integrative approaches involving ENMs and phylogeography. We would also like to thank the 3 anonymous referees whose helpful comments and suggestions improved the manuscript.

\section{References}

Allal F, Sanou H, Millet L et al. (2011) Past climate changes explain the phylogeography of Vitellaria paradoxa over Africa. Heredity, 107, 174 186.

Anderson RP (2013) A framework for using niche models to estimate impacts of climate change on species distributions. Annals of the New York Academy of Sciences, 1297, 8-28.

Anderson RP, Gonzalez I (2011) Species-specific tuning increases robustness to sampling bias in models of species distributions: an implementation with Maxent. Ecological Modelling, 222, 2796-2811.

Anderson RP, Raza A (2010) The effect of the extent of the study region on GIS models of species geographic distributions and estimates of niche evolution: preliminary tests with montane rodents (genus Nephelomys) in Venezuela. Journal of Biogeography, 37, 1378-1393.

Arenas M, Ray N, Currat M, Excoffier L (2012) Consequences of range contractions and range shifts on molecular diversity. Molecular Biology and Evolution, 29, 207-218.
Austin MP (2002) Spatial prediction of species distribution: an interface between ecological theory and statistical modelling. Ecological Modelling, 157, 101-118.

Austin MP, Van Niel KP (2011) Improving species distribution models for climate change studies: variable selection and scale. Journal of Biogeography, 38, 1-8.

Banta JA, Ehrenreich IM, Gerard S et al. (2012) Climate envelope modelling reveals intraspecific relationships among flowering phenology, niche breadth and potential range size in Arabidopsis thaliana. Ecology Letters, 15, 769-777.

Barbet-Massin M, Jiguet F, Albert CH, Thuiller W (2012) Selecting pseudo-absences for species distribution models: how, where and how many? Methods in Ecology and Evolution, 3, 327-338.

Barbujani G, Oden NL, Sokal RR (1989) Detecting regions of abrupt change in maps of biological variables. Systematic Zoology, 38, 376-389.

Barnes BV, Wagner WH (2004) Michigan Trees: A Guide to the Trees of the Great Lakes Region. University of Michigan Press, Ann Arbor, Michigan.

Barry S, Elith J (2006) Error and uncertainty in habitat models. Journal of Applied Ecology, 43, 413-423.

Barve N, Barve V, Jimenez-Valverde A et al. (2011) The crucial role of the accessible area in ecological niche modeling and species distribution modeling. Ecological Modelling, 222, 1810-1819.

Beatty GE, Provan J (2010) Refugial persistence and postglacial recolonization of North America by the cold-tolerant herbaceous plant Orthilia secunda. Molecular Ecology, 19, 5009-5021.

Beaumont MA (2002) Approximate Bayesian Computation in Evolution and Ecology. Annual Review of Ecology, Evolution, and Systematics, 41, 379-406.

Beaumont MA, Nielsen R, Robert C et al. (2010) In defence of modelbased inference in phylogeography. Molecular Ecology, 19, 436-446.

Bertorelle G, Benazzo A, Mona S (2010) ABC as a flexible framework to estimate demography over space and time: some cons, many pros. Molecular Ecology, 19, 2609-2625.

Beukema W, De Pous P, Donaire D et al. (2010) Biogeography and contemporary climatic differentiation among Moroccan Salamandra algira. Biological Journal of the Linnean Society, 101, 626-641.

Bolstad P (2008) GIS fundamentals: A First Text on Geographic Information Systems. Eider Press, White Bear Lake, Minnesota.

ter Braak CJF (1986) Canonical correspondence analysis: a new eigenvector technique for multivariate direct gradient analysis. Ecology, 67, 1167-1179.

Braconnot P, Otto-Bliesner B, Harrison S et al. (2007) Results of PMIP2 coupled simulations of the Mid-Holocene and Last Glacial Maximum \&ndash; Part 1: experiments and large-scale features. Climate of the Past, 3, 261-277.

Brown JL, Knowles LL (2012) Spatially explicit models of dynamic histories: examination of the genetic consequences of Pleistocene glaciation and recent climate change on the American Pika. Molecular Ecology, 21, 3757-3775.

Buckley TR, Marske KA, Attanayake D (2009) Identifying glacial refugia in a geographic parthenogen using palaeoclimate modelling and phylogeography: the New Zealand stick insect Argosarchus horridus (White). Molecular Ecology, 18, 4650-4663.

Busby JR (1991) A bioclimatic analysis and prediction system. In: Nature Conservation: Cost Effective Biological Surveys and Data Analysis (eds Margules CR \& Austin MP), pp. 64-68. CSIRO, Sydney, New South Wales.

Carnaval AC, Hickerson MJ, Haddad CFB, Rodrigues MT, Moritz C (2009) Stability predicts genetic diversity in the Brazilian Atlantic forest hotspot. Science, 323, 785-789.

Carpenter G, Gillison AN, Winter J (1993) DOMAIN: a flexible modeling procedure for mapping potential distributions of plants and animals. Biodiversity and Conservation, 2, 667-680.

Carstens BC, Richards CL (2007) Integrating coalescent and ecological niche modeling in comparative phylogeography. Evolution, 61, 14391454. 
Chan YL, Hadly EA (2011) Genetic variation over 10000 years in Ctenomys: comparative phylochronology provides a temporal perspective on rarity, environmental change and demography. Molecular Ecology, 20, 4592-4605.

Chan LM, Brown JL, Yoder AD (2011) Integrating statistical genetic and geospatial methods brings new power to phylogeography. Molecular Phylogenetics and Evolution, 59, 523-537.

Chapman DS, Purse BV (2011) Community versus single-species distribution models for British plants. Journal of Biogeography, 38, 1524-1535.

Chen C, Durand E, Forbes F, Francois O (2007) Bayesian clustering algorithms ascertaining spatial population structure: a new computer program and a comparison study. Molecular Ecology Notes, 7, 747-756.

Corander J, Marttinen P (2006) Bayesian identification of admixture events using multilocus molecular markers. Molecular Ecology, 15, 2833-2843.

Cordellier M, Pfenninger M (2008) Climate-driven range dynamics of the freshwater limpet, Ancylus fluviatilis (Pulmonata, Basommatophora). Journal of Biogeography, 35, 1580-1592.

Crandall ED, Treml EA, Barber PH (2012) Coalescent and biophysical models of stepping-stone gene flow in neritid snails. Molecular Ecology, 21, 5579-5598.

Crego RD, Nielsen CK, Didier KA (2013) Climate change and conservation implications for wet meadows in dry Patagonia. Environmental Conservation, CJO2013. doi: 10.1017/S037689291300026X.

Csillery K, Blum MGB, Gaggiotti OE, Francois O (2010) Approximate Bayesian Computation (ABC) in practice. Trends in Ecology E Evolution, 25, 410-418.

D'Amen M, Zimmermann NE, Pearman PB (2013) Conservation of phylogeographic lineages under climate change. Global Ecology and Biogeography, 22, 93-104.

Davis AJ, Jenkinson LS, Lawton JH, Shorrocks B, Wood S (1998) Making mistakes when predicting shifts in species range in response to global warming. Nature, 391, 783-786.

De'ath G, Fabricius KE (2000) Classification and regression trees: a powerful yet simple technique for ecological data analysis. Ecology, 81, 3178-3192.

Dormann CF, Schymanski SJ, Cabral J et al. (2012) Correlation and process in species distribution models: bridging a dichotomy. Journal of Biogeography, 39, 2119-2131.

Dyer RJ, Nason JD, Garrick RC (2010) Landscape modelling of gene flow: improved power using conditional genetic distance derived from the topology of population networks. Molecular Ecology, 19, 3746-3759.

Edwards DL, Keogh JS, Knowles LL (2012) Effects of vicariant barriers, habitat stability, population isolation and environmental features on species divergence in the south-western Australian coastal reptile community. Molecular Ecology, 21, 3809-3822.

Elith J, Graham CH (2009) Do they? How do they? Why do they differ? On finding reasons for differing performances of species distribution models. Ecography, 32, 66-77.

Elith J, Leathwick J (2007) Predicting species distributions from museum and herbarium records using multiresponse models fitted with multivariate adaptive regression splines. Diversity and Distributions, 13, 265275.

Elith J, Leathwick JR (2009) Species distribution models: ecological explanation and prediction across space and time. Annual Review of Ecology Evolution and Systematics, 40, 677-697.

Elith J, Graham CH, Anderson RP et al. (2006) Novel methods improve prediction of species' distributions from occurrence data. Ecography, 29, 129-151.

Elith J, Leathwick JR, Hastie T (2008) A working guide to boosted regression trees. Journal of Animal Ecology, 77, 802-813.

Elith J, Kearney M, Phillips S (2010) The art of modelling range-shifting species. Methods in Ecology and Evolution, 1, 330-342.

Elith J, Phillips SJ, Hastie T et al. (2011) A statistical explanation of MaxEnt for ecologists. Diversity and Distributions, 17, 43-57.

Estoup A, Lombaert E, Marin JM et al. (2012) Estimation of demo-genetic model probabilities with Approximate Bayesian Computation using linear discriminant analysis on summary statistics. Molecular Ecology Resources, 12, 846-855.

Excoffier L, Foll M, Petit RJ (2009) Genetic consequences of range expansions. Annual Review of Ecology Evolution and Systematics, 40, 481-501.

Ferrier S, Guisan A (2006) Spatial modelling of biodiversity at the community level. Journal of Applied Ecology, 43, 393-404.

Fielding AH, Bell JF (1997) A review of methods for the assessment of prediction errors in conservation presence/absence models. Environmental Conservation, 24, 38-49.

Fitze PS, Gonzalez-Jimena V, San-Jose LM et al. (2011) Integrative analyses of speciation and divergence in Psammodromus hispanicus (Squamata: Lacertidae). Bmc Evolutionary Biology, 11, 1-21.

Florio AM, Ingram CM, Rakotondravony HA, Louis EE, Raxworthy CJ (2012) Detecting cryptic speciation in the widespread and morphologically conservative carpet chameleon (Furcifer lateralis) of Madagascar. Journal of Evolutionary Biology, 25, 1399-1414.

Fortin R, Dumont P, Guenette S (1996) Determinants of growth and body condition of lake sturgeon (Acipenser fulvescens). Canadian Journal of Fisheries and Aquatic Sciences, 53, 1150-1156.

Fournier-Level A, Korte A, Cooper MD et al. (2011) A Map of Local Adaptation in Arabidopsis thaliana. Science, 334, 86-89.

Franklin J, Miller JA (2009) Mapping Species Distributions: Spatial Inference and Prediction. Cambridge University Press, Cambridge and New York.

Friedl MA, McIver DK, Hodges JCF et al. (2002) Global land cover mapping from MODIS: algorithms and early results. Remote Sensing of Environment, 83, 287-302.

Fuchs J, Parra JL, Goodman SM et al. (2013) Extending ecological niche models to the past 120000 years corroborates the lack of strong phylogeographic structure in the Crested Drongo (Dicrurus forficatus forficatus) on Madagascar. Biological Journal of the Linnean Society, 108, 658-676.

Galbreath KE, Hafner DJ, Zamudio KR (2009) When cold is better: climate-driven elevation shifts yield complex patterns of diversification and demography in an alpine specialist (American pika, Ochotona princeps). Evolution, 63, 2848-2863.

Gonzalez SG, Soto-Centeno JA, Reed DL (2011) Population distribution models: species distributions are better modeled using biologically relevant data partitions. BMC Ecology, 11, 1-10.

Goovaerts P (1998) Geostatistical tools for characterizing the spatial variability of microbiological and physico-chemical soil properties. Biology and Fertility of Soils, 27, 315-334.

Graham CH, Ron SR, Santos JC, Schneider CJ, Moritz C (2004) Integrating phylogenetics and environmental niche models to explore speciation mechanisms in dendrobatid frogs. Evolution, 58, 1781-1793.

Graham CH, VanDerWal J, Phillips SJ, Moritz C, Williams SE (2010) Dynamic refugia and species persistence: tracking spatial shifts in habitat through time. Ecography, 33, 1062-1069.

Gray LK, Hamann A (2013) Tracking suitable habitat for tree populations under climate change in western North America. Climatic Change, 117, 289-303.

Greenstein BJ, Pandolfi JM (2008) Escaping the heat: range shifts of reef coral taxa in coastal Western Australia. Global Change Biology, 14, 513528.

Guillemaud T, Beaumont MA, Ciosi M, Cornuet JM, Estoup A (2010) Inferring introduction routes of invasive species using approximate Bayesian computation on microsatellite data. Heredity, 104, 88-99.

Guisan A, Thuiller W (2005) Predicting species distribution: offering more than simple habitat models. Ecology Letters, 8, 993-1009.

Guisan A, Zimmermann NE (2000) Predictive habitat distribution models in ecology. Ecological Modelling, 135, 147-186.

Guisan A, Zimmermann NE, Elith J et al. (2007) What matters for predicting the occurrences of trees: techniques, data, or species' characteristics? Ecological Monographs, 77, 615-630.

Guo QH, Kelly M, Graham CH (2005) Support vector machines for predicting distribution of sudden oak death in California. Ecological Modelling, 182, 75-90. 
Haegeman B, Etienne RS (2010) Entropy maximization and the spatial distribution of species. The American Naturalist, 175, E74-E90.

He Q, Edwards DL, Knowles LL (2013) Integrative test of how environments from the past to the present shape the genetic structure across landscapes. Evolution, doi: 10.1111/evo.12159.

Hernandez PA, Graham CH, Master LL, Albert DL (2006) The effect of sample size and species characteristics on performance of different species distribution modeling methods. Ecography, 29, 773 785.

Hewitt G (2000) The genetic legacy of the Quaternary ice ages. Nature, 405, 907-913.

Hickerson MJ, Carstens BC, Cavender-Bares J et al. (2010) Phylogeography's past, present, and future: 10 years after Avise, 2000. Molecular Phylogenetics and Evolution, 54, 291-301.

Hickerson MJ, Stone G, Lohse K et al. (2013) Recommendations for using MsBayes to incorporate uncertainty in selecting an ABC model prior: a response to Oaks et al.. Evolution, doi: 10.1111/evo.12241.

Hijmans RJ, Cameron SE, Parra JL, Jones PG, Jarvis A (2005) Very high resolution interpolated climate surfaces for global land areas. International Journal of Climatology, 25, 1965-1978.

Hilbert DW, Ostendorf B (2001) The utility of artificial neural networks for modelling the distribution of vegetation in past, present and future climates. Ecological Modelling, 146, 311-327.

Hirzel AH, Hausser J, Chessel D, Perrin N (2002) Ecological-niche factor analysis: how to compute habitat-suitability maps without absence data? Ecology, 83, 2027-2036

Hirzel AH, Le Lay G, Helfer V, Randin C, Guisan A (2006) Evaluating the ability of habitat suitability models to predict species presences. Ecological Modelling, 199, 142-152.

Hornsby AD, Matocq MD (2012) Differential regional response of the bushy-tailed woodrat (Neotoma cinerea) to late Quaternary climate change. Journal of Biogeography, 39, 289-305.

Hortal J, Jimenez-Valverde A, Gomez JF, Lobo JM, Baselga A (2008) Historical bias in biodiversity inventories affects the observed environmental niche of the species. Oikos, 117, 847-858.

Iverson LR, Schwartz MW, Prasad AM (2004) How fast and far might tree species migrate in the eastern United States due to climate change? Global Ecology and Biogeography, 13, 209-219.

Jackson ST, Betancourt JL, Booth RK, Gray ST (2009) Ecology and the ratchet of events: climate variability, niche dimensions, and species distributions. Proceedings of the National Academy of Sciences of the United States of America, 106, 19685-19692.

Jacquez GM (1995) The map comparison problem: tests for the overlap of geographic boundaries. Statistics in Medicine, 14, 2343-2361.

Jezkova T, Jaeger JR, Marshall ZL, Riddle BR (2009) Pleistocene impacts on the phylogeography of the desert pocket mouse (Chaetodipus penicillatus). Journal of Mammalogy, 90, 306-320.

Jimenez-Valverde A (2012) Insights into the area under the receiver operating characteristic curve (AUC) as a discrimination measure in species distribution modelling. Global Ecology and Biogeography, 21, 498-507.

Kalkvik HM, Stout IJ, Doonan TJ, Parkinson CL (2012) Investigating niche and lineage diversification in widely distributed taxa: phylogeography and ecological niche modeling of the Peromyscus maniculatus species group. Ecography, 35, 54-64

Kearney M (2006) Habitat, environment and niche: what are we modelling? Oikos, 115, 186-191.

Kearney M, Porter W (2009) Mechanistic niche modelling: combining physiological and spatial data to predict species' ranges. Ecology Letters, 12, 334-350.

Kearney M, Porter WP, Williams C, Ritchie S, Hoffmann AA (2009) Integrating biophysical models and evolutionary theory to predict climatic impacts on species' ranges: the dengue mosquito Aedes aegypti in Australia. Functional Ecology, 23, 528-538.

Kitchener AC, Rees EE (2009) Modelling the dynamic biogeography of the wildcat: implications for taxonomy and conservation. Journal of Zoology, 279, 144-155.
Knowles LL (2000) Tests of Pleistocene speciation in montane grasshoppers (genus Melanoplus) from the sky islands of western North America. Evolution, 54, 1337-1348.

Knowles LL (2009) Statistical phylogeography. Annual Review of Ecology Evolution and Systematics, 40, 593-612.

Knowles LL, Alvarado-Serrano DF (2010) Exploring the population genetic consequences of the colonization process with spatio-temporally explicit models: insights from coupled ecological, demographic and genetic models in montane grasshoppers. Molecular Ecology, 19, 3727-3745.

Knowles LL, Carstens BC, Keat ML (2007) Coupling genetic and ecological-niche models to examine how past population distributions contribute to divergence. Current Biology, 17, 940-946.

Kozak KH, Wiens JJ (2010) Niche conservatism drives elevational diversity patterns in Appalachian salamanders. The American Naturalist, 176, $40-54$.

Kriticos DJ, Leriche A (2010) The effects of climate data precision on fitting and projecting species niche models. Ecography, 33, 115-127.

Kriticos DJ, Webber BL, Leriche A et al. (2012) CliMond: global highresolution historical and future scenario climate surfaces for bioclimatic modelling. Methods in Ecology and Evolution, 3, 53-64.

Latimer AM (2007) Geography and resource limitation complicate metabolism-based predictions of species richness. Ecology, 88, 1895-1898.

Lawler JJ, Ruesch AS, Olden JD, McRae BH (2013) Projected climate-driven faunal movement routes. Ecology Letters, 16, 1014-1022.

Lawson LP (2010) The discordance of diversification: evolution in the tropical-montane frogs of the Eastern Arc Mountains of Tanzania. Molecular Ecology, 19, 4046-4060.

Legendre P, Fortin MJ (2010) Comparison of the Mantel test and alternative approaches for detecting complex multivariate relationships in the spatial analysis of genetic data. Molecular Ecology Resources, 10, 831844.

Lehmann A, Overton JM, Leathwick JR (2002) GRASP: generalized regression analysis and spatial prediction. Ecological Modelling, 157, 189-207.

Lehrian S, Balint M, Haase P, Pauls SU (2010) Genetic population structure of an autumn-emerging caddisfly with inherently low dispersal capacity and insights into its phylogeography. Journal of the North American Benthological Society, 29, 1100-1118.

Leuenberger C, Wegmann D (2010) Bayesian Computation and Model Selection Without Likelihoods. Genetics, 184, 243-252.

Liu CR, Berry PM, Dawson TP, Pearson RG (2005) Selecting thresholds of occurrence in the prediction of species distributions. Ecography, 28, 385-393.

Liu C, White M, Newell G (2009) Measuring the accuracy of species distribution models: a review. In: 18th World IMACS/MODSIM Congress, Cairns, Australia.

Lobo JM, Jimenez-Valverde A, Real R (2008) AUC: a misleading measure of the performance of predictive distribution models. Global Ecology and Biogeography, 17, 145-151.

Lombaert E, Guillemaud T, Thomas CE et al. (2011) Inferring the origin of populations introduced from a genetically structured native range by approximate Bayesian computation: case study of the invasive ladybird Harmonia axyridis. Molecular Ecology, 20, 4654 4670.

Lozier JD, Aniello P, Hickerson MJ (2009) Predicting the distribution of Sasquatch in western North America: anything goes with ecological niche modelling. Journal of Biogeography, 36, 1623-1627.

Maggini R, Lehmann A, Zimmermann NE, Guisan A (2006) Improving generalized regression analysis for the spatial prediction of forest communities. Journal of Biogeography, 33, 1729-1749.

Mantel N (1967) The detection of disease clustering and a generalized regression approach. Cancer Research, 27, 209-220.

Marske KA, Leschen RAB, Buckley TR (2012) Concerted evolution versus independent evolution and the search for multiple refugia: comparative phylogeography of four forest beetles. Evolution, 66, 1862-1877. 
McCormack JE, Zellmer AJ, Knowles LL (2010) Does niche divergence accompany allopatric divergence in Aphelcoma jays as predicted under ecological speciation? Insights from tests with niche models. Evolution, 64, 1231-1244

McRae BH (2006) Isolation by resistance. Evolution, 60, 1551-1561.

Meier ES, Kienast F, Pearman PB et al. (2010) Biotic and abiotic variables show little redundancy in explaining tree species distributions. Ecography, 33, 1038-1048.

Monmonier MS (1973) Maximum-difference barriers: an alternative numerical regionalization method*. Geographical Analysis, 5, 245-261.

Morgan K, O'Loughlin SM, Chen B et al. (2011) Comparative phylogeography reveals a shared impact of pleistocene environmental change in shaping genetic diversity within nine Anopheles mosquito species across the Indo-Burma biodiversity hotspot. Molecular Ecology, 20, 4533-4549.

Moussalli A, Moritz C, Williams SE, Carnaval AC (2009) Variable responses of skinks to a common history of rainforest fluctuation: concordance between phylogeography and palaeo-distribution models. Molecular Ecology, 18, 483-499.

Neuenschwander S, Largiader CR, Ray N et al. (2008) Colonization history of the Swiss Rhine basin by the bullhead (Cottus gobio): inference under a Bayesian spatially explicit framework. Molecular Ecology, 17, 757-772.

Nielsen R, Beaumont MA (2009) Statistical inferences in phylogeography. Molecular Ecology, 18, 1034-1047.

Ortego J, Riordan EC, Gugger PF, Sork VL (2012) Influence of environmental heterogeneity on genetic diversity and structure in an endemic southern Californian oak. Molecular Ecology, 21, 3210-3223.

Patterson BD, Ceballos G, Sechrest W et al. (2007) Digital Distribution Maps of the Mammals of the Western Hemisphere, version 3.0. NatureServe, Arlington, Virginia.

Pearson R (2010) Species' distribution modeling for conservation educators and practitioners. Lessons in Conservation, 3, 56-89.

Pearson RG, Thuiller W, Araujo MB et al. (2006) Model-based uncertainty in species range prediction. Journal of Biogeography, 33, 1704-1711.

Pearson RG, Raxworthy CJ, Nakamura M, Peterson AT (2007) Predicting species distributions from small numbers of occurrence records: a test case using cryptic geckos in Madagascar. Journal of Biogeography, 34, 102-117.

Peterson AT (2011) Ecological niche conservatism: a time-structured review of evidence. Journal of Biogeography, 38, 817-827.

Peterson AT, Soberon J, Sanchez-Cordero V (1999) Conservatism of ecological niches in evolutionary time. Science, 285, 1265-1267.

Peterson AT, Papes M, Eaton M (2007) Transferability and model evaluation in ecological niche modeling: a comparison of GARP and Maxent. Ecography, 30, 550-560.

Peterson AT, Papes M, Soberon J (2008) Rethinking receiver operating characteristic analysis applications in ecological niche modeling. Ecological Modelling, 213, 63-72.

Peterson AT, Soberón J, Pearson RG et al. (2011) Ecological Niches and Geographic Distributions. Princeton University Press, Princeton, New Jersey.

Phillips SJ, Anderson RP, Schapire RE (2006) Maximum entropy modeling of species geographic distributions. Ecological Modelling, 190, 231259.

Phillips SJ, Dudik M, Elith J et al. (2009) Sample selection bias and presence-only distribution models: implications for background and pseudo-absence data. Ecological Applications, 19, 181-197.

Polly PD, Eronen JT (2011) Mammal associations in the Pleistocene of Britain: implications of ecological niche modelling and a method for reconstructing palaeoclimate. In: The Ancient Human Occupation of Britain (eds Ashton N, Lewis S \& Stringer C), pp. 257-282. Elsevier, Amsterdam.

Ralston J, Kirchman JJ (2012) Continental-scale genetic structure in a broeal forest migrant, the blackpoll warbler (Setophaga striata). The Auk, 129, 467-478.

Randin CF, Dirnbock T, Dullinger S et al. (2006) Are niche-based species distribution models transferable in space? Journal of Biogeography, 33, 1689-1703.
Ray N, Currat M, Berthier P, Excoffier L (2005) Recovering the geographic origin of early modern humans by realistic and spatially explicit simulations. Genome Research, 15, 1161-1167.

Ray N, Currat M, Foll M, Excoffier L (2010) SPLATCHE2: a spatially explicit simulation framework for complex demography, genetic admixture and recombination. Bioinformatics, 26, 2993-2994.

Ree RH, Sanmartin I (2009) Prospects and challenges for parametric models in historical biogeographical inference. Journal of Biogeography, 36, 1211-1220.

Richards CL, Carstens BC, Knowles LL (2007) Distribution modelling and statistical phylogeography: an integrative framework for generating and testing alternative biogeographical hypotheses. Journal of Biogeography, 34, 1833-1845.

Rissler LJ, Apodaca JJ (2007) Adding more ecology into species delimitation: ecological niche models and phylogeography help define cryptic species in the black salamander (Aneides flavipunctatus). Systematic Biology, 56, 924-942.

Robert CP, Cornuet JM, Marin JM, Pillai NS (2011) Lack of confidence in approximate Bayesian computation model choice. Proceedings of the National Academy of Sciences of the United States of America, 108, 1511215117.

Roberts DR, Hamann A (2012a) Method selection for species distribution modelling: are temporally or spatially independent evaluations necessary? Ecography, 35, 792-802.

Roberts DR, Hamann A (2012b) Predicting potential climate change impacts with bioclimate envelope models: a palaeoecological perspective. Global Ecology and Biogeography, 21, 121-133.

Rodder D, Lotters S (2010) Explanative power of variables used in species distribution modelling: an issue of general model transferability or niche shift in the invasive Greenhouse frog (Eleutherodactylus planirostris). Naturwissenschaften, 97, 781-796.

Row JR, Blouin-Demers G, Lougheed SC (2010) Habitat distribution influences dispersal and fine-scale genetic population structure of eastern foxsnakes (Mintonius gloydi) across a fragmented landscape. Molecular Ecology, 19, 5157-5171.

Royle JA, Chandler RB, Yackulic C, Nichols JD (2012) Likelihood analysis of species occurrence probability from presence-only data for modelling species distributions. Methods in Ecology and Evolution, 3, 545-554.

Scoble J, Lowe AJ (2010) A case for incorporating phylogeography and landscape genetics into species distribution modelling approaches to improve climate adaptation and conservation planning. Diversity and Distributions, 16, 343-353.

Segurado P, Araujo MB (2004) An evaluation of methods for modelling species distributions. Journal of Biogeography, 31, 1555-1568.

Shafer ABA, Cullingham CI, Cote SD, Coltman DW (2010) Of glaciers and refugia: a decade of study sheds new light on the phylogeography of northwestern North America. Molecular Ecology, 19, 4589-4621.

Sillero N (2011) What does ecological modelling model? A proposed classification of ecological niche models based on their underlying methods. Ecological Modelling, 222, 1343-1346.

Smith BT, Escalante P, Banos BEH et al. (2011) The role of historical and contemporary processes on phylogeographic structure and genetic diversity in the Northern Cardinal, Cardinalis cardinalis. BMC Evolutionary Biology, 11, 1-12.

Soberón J (2007) Grinnellian and Eltonian niches and geographic distributions of species. Ecology Letters, 10, 1115-1123.

Soberón J, Nakamura M (2009) Niches and distributional areas: concepts, methods, and assumptions. Proceedings of the National Academy of Sciences of the United States of America, 106, 19644-19650.

Soberón J, Peterson AT (2005) Interpretation of models of fundamental ecological niches and species' distributional areas. Biodiversity Informatics, 2, 1-10.

Sokal RR, Rohlf FJ (1981) Biometry: The Principles and Practice of Statistics in Biological Research. W.H. Freeman, San Francisco, California.

Stewart JR (2009) The evolutionary consequence of the individualistic response to climate change. Journal of Evolutionary Biology, 22, 23632375. 
Stockman AK, Bond JE (2007) Delimiting cohesion species: extreme population structuring and the role of ecological interchangeability. Molecular Ecology, 16, 3374-3392.

Stockwell D, Peters D (1999) The GARP modelling system: problems and solutions to automated spatial prediction. International Journal of Geographical Information Science, 13, 143-158.

Stockwell DRB, Peterson AT (2002) Effects of sample size on accuracy of species distribution models. Ecological Modelling, 148, 1-13.

Svenning JC, Flojgaard C, Marske KA, Nogues-Bravo D, Normand S (2011) Applications of species distribution modeling to paleobiology. Quaternary Science Reviews, 30, 2930-2947.

Swenson NG (2006) GIS-based niche models reveal unifying climatic mechanisms that maintain the location of avian hybrid zones in a North American suture zone. Journal of Evolutionary Biology, 19, 717-725.

Synes NW, Osborne PE (2011) Choice of predictor variables as a source of uncertainty in continental-scale species distribution modelling under climate change. Global Ecology and Biogeography, 20, 904-914.

Taubmann J, Theissinger K, Feldheim KA et al. (2011) Modelling range shifts and assessing genetic diversity distribution of the montane aquatic mayfly Ameletus inopinatus in Europe under climate change scenarios. Conservation Genetics, 12, 503-515.

Telenius A (2011) Biodiversity information goes public: GBIF at your service. Nordic Journal of Botany, 29, 378-381.

Thornton K, Andolfatto P (2006) Approximate Bayesian inference reveals evidence for a recent, severe bottleneck in a Netherlands population of Drosophila melanogaster. Genetics, 172, 1607-1619.

Thuiller W, Araujo MB, Lavorel S (2003) Generalized models vs. classification tree analysis: predicting spatial distributions of plant species at different scales. Journal of Vegetation Science, 14, 669-680.

Thuiller W, Brotons L, Araujo MB, Lavorel S (2004) Effects of restricting environmental range of data to project current and future species distributions. Ecography, 27, 165-172.

Thuiller W, Lafourcade B, Engler R, Araujo MB (2009) BIOMOD - a platform for ensemble forecasting of species distributions. Ecography, 32, 369-373.

Van Niel KP, Laffan SW, Lees BG (2004) Effect of error in the DEM on environmental variables for predictive vegetation modelling. Journal of Vegetation Science, 15, 747-756.

Wagner HH, Fortin MJ (2013) A conceptual framework for the spatial analysis of landscape genetic data. Conservation Genetics, 14, 253-261.

Walker PA, Cocks KD (1991) HABITAT: a procedure for modeling a disjoint environmental envelope for a plant or animal species. Global Ecology and Biogeography Letters, 1, 108-118.

Warren DL (2012) In defense of 'niche modeling'. Trends in Ecology \& Evolution, 27, 497-500.

Warren DL, Seifert SN (2011) Ecological niche modeling in Maxent: the importance of model complexity and the performance of model selection criteria. Ecological Applications, 21, 335-342.

Warren DL, Glor RE, Turelli M (2008) Environmental equivalency versus conservatism: quantitative approaches to niche evolution. Evolution, 62, 2868-2883.

Warren DL, Glor RE, Turelli M (2010) ENMTools: a toolbox for comparative studies of environmental niche models. Ecography, 33, 607-611.

Wegmann D, Excoffier L (2010) Bayesian inference of the demographic history of chimpanzees. Molecular Biology and Evolution, 27, 1425-1435.

Wegmann D, Currat M, Excoffier L (2006) Molecular diversity after a range expansion in heterogeneous environments. Genetics, 174, 2009-2020.
Wegmann D, Leuenberger C, Neuenschwander S, Excoffier L (2010) ABCtoolbox: a versatile toolkit for approximate Bayesian computations. BMC Bioinformatics, 11, 1-7.

Wenger SJ, Olden JD (2012) Assessing transferability of ecological models: an underappreciated aspect of statistical validation. Methods in Ecology and Evolution, 3, 260-267.

Werneck FP, Nogueira C, Colli GR, Sites JW, Costa GC (2012) Climatic stability in the Brazilian Cerrado: implications for biogeographical connections of South American savannas, species richness and conservation in a biodiversity hotspot. Journal of Biogeography, 39, 1695-1706.

Wieczorek J, Guo QG, Hijmans RJ (2004) The point-radius method for georeferencing locality descriptions and calculating associated uncertainty. International Journal of Geographical Information Science, 18, 745-767.

Williams JW, Jackson ST (2007) Novel climates, no-analog communities, and ecological surprises. Frontiers in Ecology and the Environment, 5, 475-482.

Wisz MS, Pottier J, Kissling WD et al. (2013) The role of biotic interactions in shaping distributions and realised assemblages of species: implications for species distribution modelling. Biological Reviews, 88, 15-30.

Wooten JA, Camp CD, Rissler LJ (2010) Genetic diversity in a narrowly endemic, recently described dusky salamander, Desmognathus folkertsi, from the southern Appalachian Mountains. Conservation Genetics, 11, 835-854.

Zellmer AJ, Knowles LL (2009) Disentangling the effects of historic vs. contemporary landscape structure on population genetic divergence. Molecular Ecology, 18, 3593-3602.

\section{Data Accessibility}

This review is based on data already available in ISI Web of Science.

\section{Supporting Information}

Additional Supporting Information may be found in the online version of this article:

Fig. S1 Schematic describing iDDC (integrative distributional, demographic, and coalescent modelling). Using information on the local habitat suitabilities derived from ENMs generated for different time points in the past (a), a time forward demographic simulation using the program SPLATCHe 2 (Ray et al. 2010) is conducted, where local carrying capacities and migration probabilities of individuals varies across the landscape (b). Based on this ENM-informed demographic history, coalescent simulations are used to generate patterns of genetic variation (c). By simulating over a broad range of parameter sets, as specified by priors derived from alternative models, expectations for patterns genetic data, as characterized using summary statistics (e.g. $F_{\mathrm{ST}}$ and Tajima's D), can be generated under an ABC approach and compared with summary statistics obtained from empirical data (d) (for details see Beaumont 2002; Csillery et al. 2010). Note that tools to perform these analyses have already been developed and are freely available (e.g. Ray et al. 2010; Wegmann et al. 2010). 